\title{
Who Now Needs Sociology?: TRANSDISCIPLINARITY Vs. TRADITION
}

DALIBOR MišINA

Abstract. The aim of the paper is to review the current Canadian debate about the future of sociology, centered on two sets of claims: William Carroll's vision for a transdisciplinary future of the social science and humanities (i.e. the transdisciplinarity argument) (Carroll 2013); and Antony J. Puddephatt \& Neil McLaughlin's counter-vision for a sociology bound by its traditional disciplinary boundaries (i.e. the traditionalism argument) (Puddephatt and McLaughlin 2015). The paper provides an analysis of the debate in question and argues that Carroll's and Puddephatt \& Neil McLaughlin's reflexive diagnostics regarding the future of sociology offer two distinct, and competing, understandings of the discipline's nature, purpose and relevance, as well as two different sensibilities regarding an audience the discipline of sociology is, or ought to be, speaking to. In addition, an argument put forth is that Carroll's public-political and Puddephatt \& McLaughlin's professional-organizational models of sociology have important implications both for mapping out the future trajectories of the discipline, and for gauging sociology's role and position within, and relationship to, the 'universe' of society.

Keywords: Sociology, transdisciplinarity, tradition, public-political model of sociology, professional-organizational model of sociology

\section{INTRODUCTION}

S' 2 ociology — of what kind, to what end, and for whom?' Arguably, this has been the question haunting the discipline since its very inception. Ever since Marx's (in)famous Thesis Eleven (Marx 1978) and the qualification of Weber's work as a 'dialogue with the intellectual ghost of Karl Marx' (Zeitlin 1987), sociology has been, one way or another, on a quest to understand and define its nature, its purpose and relevance, and its audiences (see Friedrichs 1970: 57-110; Levine 1995). In many respects, this quest has been one of the major fires fueling the discipline's engine and, certainly, one of the focal points of (what ap- 
pear to be) never-ending and ever-expanding attempts at sociological reflexive diagnostics. Indeed, one could argue that the question of 'sociology — of what kind, to what end, and for whom?' has been the question informing the most fundamental problematique the discipline has set for itself. And if sociology's past is a(ny) predictor of sociology's future, the problematique of discipline's relevance is not expected to go away any time soon, if ever.

But why is sociology (almost) obsessed with the question of its continuing disciplinary relevance? The roots of the answer, I believe, stretch back to the French proto-sociologist Saint-Simon and his pioneer attempts to define and develop sociology and the 'science of man', which, for him, really meant framing sociology as the positive-scientific means of social engineering mandated to propel society of the day into its better and brighter (i.e. orderly and progressive) future (Saint-Simon 1974). Cast in this way, sociology was, as far as Saint-Simon was concerned, a science of the 'higher (if not the highest) order' bound by its pledge to societal - and, thus, overall human - betterment. This, in turn, made sociology a special scientific enterprise set up not in the name of 'science for science's sake' but in the name of 'science for society's sake'. SaintSimon's vision of sociology, in other words, was that of science with a mission, where sociology's ability to accomplish that mission was in direct proportion to the discipline's relevance and, at the end of the day, its raison d'être. Period.

Needless to say, not all sociologists who followed (fully) embraced Saint-Simon's vision of the discipline. However, even those who advocated a more 'value-free' and/or 'disengaged' version of sociology argued that, ultimately, the discipline ought to say something meaningful about society, or some of its segments - that, in other words, the task of sociology ought to be generating relevant knowledge of, and about, society. Otherwise, what is the point of 'committing sociology'? In this sense, the tie that binds all sociologists, regardless of their particular sociological bent, is a commitment to the unbreakability of the link between sociology and society, and the belief that 'sociological imagination' (to use Mills' metaphor (Mills 1959)) is the most productive way of getting a handle on the matters and affairs of society. The 'sociological choir' gets a bit more dissonant and polymorphous when it gets down to the specifics of 'how to' and 'what about' in relation to society, but, despite this, all of its members are on the same page, and in tune, when it comes to the fundamentals of a 'sociology libretto'.

The consequence of this foundational assumption regarding sociology is, I believe, the discipline's 'permanent anxiety' about its own ability to rise to the task of delivering meaningful and relevant knowledge 
about the 'universe' of society. This sense of sociological anxiety is particularly heightened in times of societal shifts and transformations, when there is a perception that society — and the world in general — is changing and transforming into something different and unfamiliar, and when, in consequence, there seems to be a (new) wave of sociological reflexive diagnostics about the question of 'sociology — of what kind, to what end, and for whom?' (for a Polanyian periodization of 'three waves' of sociology (utopian, policy, and public), see Burawoy 2005: 156-59). But why is this so? If Urlich Beck (2007) is right, this kind of sociological anxiety reflects the deeper problem of sociology's increasingly 'zombie status', which is nothing but an indication of the discipline's conceptual and methodological outdatedness, manifested as an awareness of the inability to adequately analyze and understand the society — and the world — of today. From Zygmunt Bauman's viewpoint (Bauman 1988), the anxiety is a consequence of sociologists being decentered from a position of official (i.e. government sanctioned) 'truth legislators' on all things society, and of the corresponding downgrading of sociological knowledge from a 'crown status' of the knowledge of/about society to the much less flattering and convincing position of a 'relativisable language game'. However the matter in question is casts (and Beck's and Bauman's positions are most certainly not the only ways of doing it), the end proposition appears to be that the tidal quests for the answers to 'sociology — of what kind, to what end, and for whom?' are, at the end of the day, about sociology trying to reframe/recast itself in a way that would extend its 'use value' and thus reaffirm its continuing relevance, set against an implicit or explicit anxiety that this relevance is, or might be, threatened by the everchanging 'universe' of society and the discipline's standing within it.

With this as a general backdrop, my aim here is to review the current Canadian debate about the future of sociology, centered on two sets of claims: William Carroll's vision for a transdisciplinary future of the social science and humanities (i.e. the transdisciplinarity argument) (Carroll 2013); and Antony J. Puddephatt \& Neil McLaughlin's counter-vision for a sociology bound by its traditional disciplinary boundaries (i.e. the traditionalism argument) (Puddephatt and McLaughlin 2015). My argument, in providing an analysis of the debate in question, is thatwhile on the same quest of dealing with the question of "sociology —of what kind, to what end, and for whom?'-Carroll's and Puddephatt \& Neil McLaughlin's reflexive diagnostics offer two distinct, and competing, understandings of the sociology's nature, purpose and relevance, as well as two different sensibilities regarding an audience the discipline is, or ought to be, speaking to. In addition, I argue that Carroll's publicpolitical and Puddephatt \& McLaughlin's professional-organizational models of sociology have important implications both for mapping out 
the future trajectories of the discipline, and for gauging sociology's role and position within, and relationship to, the 'universe' of society.

\section{Sociology-as-Nexus: The Transdisciplinarity Argument}

In Discipline, Field, Nexus: Re-Visioning Sociology, William Carroll offers what can be termed as the transdiciplinarity argument regarding the future of sociology. His task in the article is to take pulse of the most recent wave of debates and arguments about sociology's 'identity crisis', and to propose "a re-visioning of sociology and of its relationship to the late-modern world it inhabits" (2013: 1). Carroll's fundamental point, in casting his argument, is that a meaningful sociology ought to be conceived "not as a self-contained discipline but as a nexus, a field whose permeability, dense connectivity to other fields and "critical interdisciplinarity" are prime assets ... that can strengthen sociology's capacity to understand our troubled world and to defend and enrich practices that may portend a better future" (2013: 4, in-text reference omitted).

The grounding point for Carroll's transdiciplinarity argument is to identify sociology's object of analysis. Although throughout the paper the latter is referred to as "capitalism", "late-modern world", "the social", and "human condition", its most precise qualification would be 'human condition within capitalist modernity'. In Carroll's view, the task of sociology is to illuminate the state of 'social agency' (i.e. human condition) within the existing 'social structure' (i.e. capitalist modernity), and to do so as reflexively and as diagnostically as possible. In casting sociology's object of analysis in this way, and doing it largely from the Frankfurt School/Critical Theory position, Carroll also sets up sociology's normative task as being in service of "creating the conditions for a reflexive, participatory-democratic way of life" (2013: 20). Thus, Caroll's vision for sociology is not of 'science for science's sake' but, rather, of 'science for society's - i.e. people's - sake'. In other words, it is the vision of sociology where the ultimate purpose of analyzing capitalist modernity is to understand it so as to be able to change it through transformative democratic practices. As Carroll puts it,

the task is to understand the social forces, embodied practices, identities, discourses, and relations that have come to prevail (or that have become marginalized) - to trace out why they have come to prevail, the emergent structures that sustain them, the consequences for our lives, and the prospect for alternatives. This is an interpretive, diagnostic project that seeks to understand the causal linkages between past, present, and future, so as to clarify for ourselves "the struggles and wishes of the age." (2013: 18-19) 
In Carroll's view, an indispensable prerequisite for accomplishing this is sociology freeing itself from the confines of disciplinary rigidity and embracing transdisciplinarity as its modus operandi.

But why? Why is sociology, bound by its own disciplinary parameters, not capable of accomplishing the task of understanding the reality of capitalist modernity? Put simply, it is because the anatomy of capitalist modernity is too complexly multilayered and multifaceted to be successfully analyzed and understood by an insular social science discipline - sociology, or any other. In other words, the crux of the problem is that the nature of capitalist modernity (or any social phenomenon, for that matter) escapes the parceling out of knowledge resulting from the creation and reinforcement of disciplinary boundaries, because it does not lend itself to the slicing up into "the historical", "the social", "the political", "the economic", "the cultural", "the psychological", etc. The tendency of social science disciplines, according to Carroll, is to take the latter as distinct 'pieces' that can be singled out and studied in their own right, separate and in isolation from 'the rest', whereas, in reality (i.e. from the viewpoint of critical realism), all of the 'pieces' are interconnected, interdependent, and inseparable facets of one dynamic, emergent, and stratified historical particularity. In other words, given that the anatomy and reality of capitalist modernity is inherently 'transdisciplinary' and "continuously breaching the disciplinary boundaries", its analysis and understanding ought to be premised on "a strategy that, within the current state of affairs, is plainly transdicsiplinary" (Carroll 2013: 10). In this context, Carroll's vision for sociology is one of "the nexus of contemporary social science's fields ... that offers a point of leverage toward a unified, postpositivist social science" (2013: 16; 21, original emphasis).

At its core, the transdisciplinarity argument is Carroll's call for meaningfully relevant sociology-i.e. a sociology engaged in "critical investigation into the social condition of humanity whose footprint now covers the globe" (2013: 22, in-text reference omitted), and "aligned more with lifeworld than with system" (2013: 21). In other words, it is a call for a public sociology grounded in the principle of "critical transdisciplinarity that breaches the enclosures of disciplinary social science", and motivated by the commitment to "publics whose practices press up against and challenge capitalist modernity's reified structures" (Carroll 2013: 21; 20). In Carroll's view, this kind of sociology is at odds with the conventional "circle-the-wagons" approach of reinforcing and policing disciplinary borders and boundaries in the face of 'identity crisis', which, at the end of the day, is but a 'strategic move' in the name of maintaining and re-establishing disciplinary credibility and academic 
authority under the condition of "[n]eoliberal governance [that] has only intensified disciplinary rivalry, muting possibilities for breaking out of siloes as each unit competes for funding under increasingly market-based conditions" (2013: 15, in-text references omitted). Thus understood, the transdisciplinarity argument is a call for sociology of a different kind and order-i.e. a sociology that prioritizes lifeworld relevance over system's formal acknowledgement and approval, and embraces real-world engagement over institutional(ised) status maintenance.

\section{Sociology-as-Pluralist Discipline: The Traditionalism Argument}

Written as a response to the transdisciplinarity argument, Critical Nexus or Pluralist Discipline?: Institutional Ambivalence and the Future of Canadian Sociology by Antony J. Puddephatt and Neil McLaughlin (2015) is both a critique of, and an attempt to offer an alternative to, Carroll's vision for the future of sociology. As a critique, the article provides 'reality check' of a sort by 'testing' Carroll's ideas against the current academic and broader social-political environment within which the discipline of sociology exists and operates. As an alternative vision for sociology, the paper outlines what the authors identify as a model "not rooted in any particular philosophy of science, political ideology, theoretical paradigm, or methodological approach", and "built around a pluralist commitment to intellectual diversity, respecting the "chaos" that ultimately drives our research forward and reshapes the intellectual parameters of our field over time" (Puddephatt and McLaughlin 2015: 312). What ties the two together is a premise that, at the end of the day, sociology is first and foremost a scholarly enterprise, and that, therefore, any arguments and/or ideas about the future of the discipline ought to take this as their jumping-off point.

On the critique front, the key question that Puddephatt \& McLaughlin raise (albeit implicitly) is 'how does the transdisciplinarity argument square against the institutional realities of sociology as a scholarly enterprise?' In short, the answer is, 'not all that well'. While, in general, sympathetic to-if not (fully) supportive of-sociology's transdiciplinary propensity, Puddephatt \& McLaughlin caution against it on the grounds that "[t]his transdisciplinary world of scholarship, if it was ever actually realized, would not have sociologists in a privileged position in the social sciences, and, in contrast, would only make us more vulnerable" (2015: 314). In other words, the (full) 'transdisciplinarity turn' in sociology ought to be avoided because it would weaken rather than strengthen the discipline. But why? As Puddephatt \& McLaughlin's institutional 
analysis of sociology's place in higher education points out, it is because the transdisciplinarity turn is at odds with (1) the discipline-centric nature of academia, "institutionalized in the training of scholars, the establishment of programs, and academic conferences and journals, resulting in manageable boundaries for scholars and students" (2015: 8), as well as with (2) the institutional advantages of qualified expertise, intellectual autonomy and standards of research, and accumulated cultural capital brought to sociology (and other lower-status disciplines in the social sciences) through disciplinary consolidation. Moreover, in the context of the current neo-liberal economic restructuring, the rhetoric of interdisciplinarity has been co-opted by administrators and used as an instrument to "leverage for institutional change and take advantage of trends and niche advertising to relatively naïve and under-serviced students, while jeopardizing the very architecture of the modern university" (Puddephatt and McLaughlin 2015: 315). Finally, the critical realism underpinnings of the transdisciplinarity vision add to, rather than counter, sociology's 'reputation deficit' by playing right into the hands of conservative critics who, by and large, see the discipline as excessively left-leaning dogmatic enterprise rather than a credible scholarly undertaking. For all these reasons, Puddephatt \& McLaughlin argue that Carroll's argument, while not without merits, does not have much purchase when set against the actual academic and broader social-political realities that inform and shape sociology as a scholarly discipline.

As a counter-vision, Puddephatt \& McLaughlin offer what can be termed as the traditionalism argument which-like their critique of the transdisciplinarity argument - is premised on the notion that, above all, sociology ought to be thought of in academic terms, and that, therefore, "[t]he legitimacy of sociology depends on our success in establishing our credibility as a scholarly enterprise" (2015: 320$)$. The crux of the argument is that, as an academic discipline, sociology is centered on scholarly knowledge production, and that, therefore, any vision for its future has to be grounded in the consideration of institutional conditions most conducive to the furthering of this central task. From this viewpoint, the key question to address is 'how to envision - and achieve-a realistic institutional strategy of knowledge production for the discipline of sociology?'.

The roots of the answer are in the notion that scholarly knowledge production is at its best when the standards of scholarly practice (i.e. established philosophical, theoretical, and methodological traditions, frameworks and procedures) are recognized, observed, and at the forefront of academic research, and that, therefore, the credibility and legitimacy of a(ny) scholarly enterprise rests on the ability to maintain 
and reinforce those standards across its 'academic field'. With regards to sociology, this means ensuring that the standards of 'good scholarship' continue informing all varieties of sociological research and knowledge production. More specifically, dealing with the question of a realistic institutional strategy requires recognizing that sociology exists and operates in a state of "institutional ambivalence" (i.e. competing and contradictory pressures of scholarly knowledge production) that generates conflicting roles and responsibilities for sociology practitioners. Puddephatt $\&$ McLaughlin identify four sources of institutional ambivalence: disciplinary vs. interdisciplinary knowledge production; political vs. analytical research approach; professional vs. public research audience; and local/national vs. global research scope (2015: 321-26). Within each of these continuums of knowledge production, " $[\mathrm{t}]$ he individual academic is pulled into two opposing directions, of which both have advantages and disadvantages" (2015: 322). The key point in identifying and detailing the sources of institutional ambivalence is to map out the intellectual "chaos" of sociology that all of the discipline's practitioners have to negotiate in their pursuits of knowledge. As well, it is to impress that sociological knowledge production is 'messy' and without a clearly delineated path or course, and that, in this sense, it is very much a 'directionless affair'. Given this, Puddephatt \& McLaughlin caution against the dangers of slipping into 'pathological extremes' within each of the continuums, and advocate the importance of 'riding' a reasonable middle ground.

At its core, the traditionalism argument is Puddephatt \& McLaughlin's call for maintaining and reinforcing the credibility of sociology as a scholarly enterprise by respecting its well established disciplinary tradition of social, political, ontological, epistemological, theoretical and methodological diversity, and by harnessing its sovereign power of "energized dynamism" (2015: 329). Its centerpiece is a proposition that the best way to achieve this is to "push for knowledge integration through convergent institutional norms in form" on the basis of "a balanced and transparent reward structure ... necessary to assure professional competence, fair standards of practice, enhanced knowledge integration, and credible scholarly and public communication" (Puddephatt and McLaughlin 2015: 312, original emphasis). In Puddephatt \& McLaughlin's view, this vision for sociology is at odds with the one advocated by Carroll which - under the guise of transdisciplinarity — seeks to force the discipline's diversity into one theoretical-philosophical box and filter its research practices through political litmus tests. Thus understood, the traditionalism argument is a call for sociology of a different kind and order-i.e. a sociology that prioritizes sound scholarship over academic 
politicking, and embraces intellectual autonomy over a straitjacket of dogmatism.

\section{Transdisciplinarity vs. Tradition: An Assessment of the Debate}

The transdisciplinarity vs. tradition debate maps out two different, and divergent, models of sociology: public-political (put forth by Carroll), and professional-organizational (offered by Puddephatt \& McLaughlin). While both models are, essentially, attempts to define a meaningful sociology, the pictures of the discipline they paint are of rather different tones, shades, and textures. The one painted by the public-political model is of a transdisciplinary and intellectually engaged sociology, servicing transformative democratic practices in the late-modern capitalist world. In contrast, the picture painted by the professional-organizational model is one of a pluralist academic discipline, centered on scholarly knowledge production in an environment of institutional ambivalence.

\section{The Public-Political Model: An Assessment}

If assessed against the question of 'sociology — of what kind, to what end, and for whom?', the public-political model clearly frames the discipline in terms of its nature, its purpose and relevance, and its audiences. Thus, with regards to the 'sociology — of what kind' portion of the question, the model maps out the vision for sociology as a transdisciplinary and intellectually engaged nexus, grounded in the philosophical and ontological assumptions of critical realism. The transdisciplinarity argument is well taken, and sociology (as much as any other social science discipline) perhaps does stand to draw benefit from broadening its intellectual, theoretical, and methodological horizons by heeding the notion that social reality is emergent, stratified, historical and particular, and - as an object of social-scientific investigative interests - in need of a more multifaceted and sophisticated academic 'apparatus' that goes beyond the established disciplinary boundaries. However, arguing this without providing at least a preliminary vision of the 'how-to' specifics does not get one very far. In other words, the basic - and fundamentalquestion here is: 'how does one actually do a successful and constructive transdisciplinary work?' While, in principle, one can embrace and commit to transdisciplinarity, this does not mean that one is actually capable of doing transdisciplinary work. At the risk of caricaturing things, the public-political model needs to offer more than a general premise that 'everything is related to everything' and that, therefore, 'everything matters' when we analyze social reality, or some of its aspects. Puddephatt 
\& McLaughlin's remark that "[s]ome of the research ... that passes itself off as "interdisciplinary" is actually more like "nondisciplinary" work, involving little more than common sense logic and descriptive data" (2015: 318) zeroes in on the issue at hand. All to say that the criteria and standards for establishing 'transdisciplinary research competence' ought to be of crucial importance to anyone that makes - or takes - the transdisciplinarity argument with any degree of seriousness, especially when that argument is coupled with an idea of 'engaged knowledge' with the real-world consequence.

Which brings us to the 'sociology - to what end' part of the question. According to the public-political model, the principal, and ultimate, aim of sociological knowledge is to contribute to "creating the conditions for a reflexive, participatory-democratic way of life", and inform transformative practices needed to move beyond the problematic ways of life (Carroll 2013: 20, 11). In other words, it is to figure as a catalyst for making the world in which we live a better place. Although certainly inspiring, the casting of sociological knowledge as an agent of conscientization (to use Friere's terminology (2000)) does call attention to the matter of knowledge dissemination and application. While, as sociologists, we may have a (relative) control over our ideas and our knowledge production, we are really not in charge when it comes to how our knowledge gets disseminated and applied. In other words, once what we generate through our research efforts enters the public pool of knowledge, it is, so to speak, 'up for grabs' by anyone, anytime, anywhere. We, as sociologists, have no control over who will end up using our 'intellectual labour', how, and at what point. We also have no control over how long it will take for our ideas to reach the public and/or become part of 'popular collective consciousness', or if this will indeed ever happen. The fact that, for example, it took some 160 years for Marx's analysis of class polarization in capitalist society to seep into our popular collective consciousness as the ' $1 \%$ vs. $99 \%$ ' catchphrase is perhaps a good illustration and reminder that the matter of public acceptance or impact of the knowledge we generate is, for all practical purposes, out of our hands. All of this is not to say that the public-political model's answer to 'sociology — to what end?' has no real purchase. It is, rather, to point out that the process of sociological knowledge becoming integral to a 'reflexive, participatory-democratic way of life' and to 'informing transformative practices' is much longer, more complex and uncertain than is often imagined or assumed. Does this mean that we should give up on the idea? Not at all. What it means is that we should perhaps calibrate our expectations and think of the public-political model's stance on the 
end-purpose of sociological knowledge as an aspirational rather than immediate goal.

'Sociology-for whom?' Grounded in the notion that sociological knowledge is an agent of conscientization leading to social change, the public-political model's answer is fairly straightforward: for the public-i.e. the people wanting to change the world. This, of course, is an idea that goes back to Marx and all those who follow in his footsteps, and is based on the logic that once the people (or, in Marx's case, members of the proletariat) are intellectually empowered through "critical knowledge" and capable of 'seeing through' the system, they will 'revolutionize' and demand - or, more likely, be the agents of - transformative changes. While certainly not without merit and appeal, the idea of sociological knowledge being a means of a revolutionary intellectual empowerment is not without its problems. Ever since Weber's critique of Marx's understanding of social class, the notion that 'the people' - or 'the public' - can be thought of as a single, homogenous group has been repeatedly brought into question and challenged. And so has the idea that 'the people' — or 'the public' — are of the same mind, as it were, and therefore have the same (revolutionary) interests. Thus, if sociology gets cast as a "sociology for people", or as a "sociology for the changing world" (as the public-political model does (see Carroll 2013: 20)), the questions one ought to entertain seriously are 'who are 'the people' sociology is meant to be for?', and 'what is it that 'the people' wish to change?' (on public sociology, its mandate and its audiences, see Agger 2007; Clawson et al. 2007; Nichols 2007). Unfortunately, the publicpolitical model falls somewhat short on handling these altogether successfully. Closest to an answer one gets is pluralization of 'the public' into 'publics', meant to indicate a broad range of public groups with their own set of presumably progressive democratic ideas and priorities. This is followed up by a recommendation that sociology ought to open itself to what Habermas (1987) calls "life-world" and form an "organic relationship' with the publics, in the context of which the discipline's research agendas are to be both motivated by, and motivate, the publics' interests, priorities, and actions. The assumptions here are that public groups are inherently progressive and therefore interested in transformative changes, and that they are interested in sociology and what it has to offer. While this may certainly hold true in some cases and for some public groups, it is quite unlikely that it holds true for all of them, across the board. Even if sociology's audience is narrowed to 'progressive publics', this does not fully solve the problem of assuming that 'being progressive' equals seeing the world in the same way and, therefore, pushing in the same direction in terms of transformative changes. As well, 'being 
progressive' does not necessarily equal to being receptive to, and having use for, sociological knowledge. All to say that, while intuitively sound and most certainly inspiring, the notion that sociology ought to be the 'people's enterprise' and that, on the flipside, 'the people' ought to see it as such may have more of a rhetorical than real purchase. This, of course, does not mean that the idea of sociology servicing the good of the publics has no value and that one should therefore abandon it. What it means, rather, is that the connection between sociology and whoever its fruits of knowledge are meant for is more complex and less straightforward compared to its casting by the public-political model.

All of this brings us back to the centerpiece of the public-political model - a proposition that sociology ought to take the transdisciplinarity turn and reframe itself as "the nexus of contemporary social science's fields ... that offers a point of leverage toward a unified, postpositivist social science" (Carroll 2013: 16; 21, original emphasis). If taken to its logical conclusion, what the transdisciplinarity turn ultimately leads to is the end of sociology and, for that matter, all other social science disciplines, and their morphing into a 'unified, postpositivist science'. Recasting sociology as a nexus thus appears to be a step towards the discipline 'withering away'. The question to ask here, therefore, is, 'do we want the end of sociology, and what is to be gained by it?' According to Puddephatt \& McLaughlin, there are significant and serious intellectual, organizational, professional, and institutional drawbacks and consequences to the transdisciplinarity turn, which not only threaten our commitment to "sociology as a discipline and stock of collectively shared knowledge that is rooted in generations of ideas, theories, methods, findings and insights" (2015: 318), but also jeopardize the very existence of sociology as a distinct scholarly social science field. From the viewpoint of the public-political model, however, the transdisciplinarity turn is both necessary and inevitable if social science is to be able to continue claiming any relevance in the future: it is necessary because it is ever more apparent that disciplinary divisions are an increasingly outmoded way to produce meaningful (i.e. relevant) knowledge about the world of today; it is inevitable because it is the only way for social sciences to avoid transitioning from 'being' into 'nothingness'. Yes, the transdisciplinarity turn does lead to an end of social sciences as we know them today. But, it also leads to a new kind of post-disciplinary social science ready to embrace the contributions of all willing to step into the new phase of intellectual enterprise. Thus, as far as the public-political model is concerned, the end is, ultimately, the new beginning - a New Hope, if you will. 


\section{The Professional-Organizational Model: An Assessment}

In contrast to the public-political model, the professional-organizational model paints the picture of sociology as a pluralist academic discipline, centered on scholarly knowledge production in an environment of institutional ambivalence. What this suggests, of course, is that the professional-organizational model provides a different set of answers to 'sociology — of what kind, to what end, and for whom?'. Regarding the 'sociology — of what kind' part of the question, the model clearly positions sociology within an academic terrain and argues that the discipline is, first and foremost, a scholarly enterprise with rich disciplinary history and tradition, and that, therefore, our utmost obligation, as sociologists, is to ensure sociology's existence as a sound and respectable filed of scholarship. This, the argument goes, is important for two reasons: (1) to ensure the optimal knowledge production; and (2) to ensure the discipline's continuing existence within an academic institution of university. The most productive way to accomplish both is to prioritize the existing sociological tradition and-while welcoming (the already present) interdisciplinarity - avoid the push towards transdisciplinarity. While well worth making, the argument for the continuing disciplinary and institutional presence of sociology nevertheless calls attention to the matter of sociology's disciplinary history and tradition. If George Ritzer's (1975) suggestion about sociology being a 'multi-paradigm discipline' is taken seriously, its logical endpoint is a realization that sociology does not have a single - or singular - disciplinary history and tradition but, rather, the multiple ones (see also Levine 1995). So the question to ask, in the context of the professional-organizational model's proposition, is 'which - or whose - disciplinary history and tradition are we talking about?'. One way to answer is to say, 'all of them' (which seems to be Puddephatt \& McLaughlin's position). However, if for no other reason, this is problematic because of the matter of incompatibility and, in some cases, incommensurability between different streams of sociology. In other words, by answering 'all of them', we are effectively committing to the idea of 'sociologies' rather than 'sociology', which, in turn, invites the question of whether it is possible, or realistic, to expect that sound sociological scholarship argued for by the professional-organizational model can be built on the foundations of divergent disciplinary trajectories. The answer here appears to be, 'not very likely'. If so, we are back to the question of 'which-or whose-disciplinary tradition?'.

The issue here is that the professional-organizational model appears to see sociology's scholarly well-being as a means to a larger end (i.e. the discipline's continuing existence within academia) rather than an 
end to itself. This, in turn, necessitates that sociology's criteria of 'good scholarship' be cast in a way that resonates with not only the discipline's practitioners but also - and perhaps more importantly - with 'sociology outsiders' but 'academia and university insiders' (i.e. university administrators, institutional decision-makers, etc.). Inevitably, this leads to selective appropriation of the discipline's history and tradition as a means of shaping and presenting sociology as a reputable scholarly field. Although not casting it in exactly these terms, Puddephatt \& McLaughlin allude to the matter at hand by suggesting that sociology's scholarly reputation is (at least in part) tied to its practitioners' willingness and ability to publish their work in flagship, high-impact, sociological journals (which, by and large, are not Canadian), as well as by referring to sociology's 'reputation deficit' within the present conservative political climate in Canada (2015: 21, 13). The suggestion here seems to be that a certain kind of sociology-i.e. sociology credentialized by the 'academic guardians of the discipline's universe' and appealing to society's 'political (and other) custodians' - has a more scholarly ring to it and therefore more purchase within not only an academic community but also - and not unimportantly — within a broader community of society. This, in turn, makes this particular version of sociology more easily 'presentable' as a credible scholarly discipline worthy of continuing academic support and societal patronage. In other words, building and maintaining sociology's scholarly reputation is a matter that rests - perhaps to a considerable degree - on 'extra-sociological factors' that need to be, and are, taken into account. Whether we, as sociologists, like to admit it to ourselves, they do impact how we 'read' our disciplinary history and tradition, and what and how much of it we end up incorporating into our notion of 'good scholarship' and its benefits to sociology's status and existence within and outside of academia.

In terms of 'sociology - to what end?', the professional-organizational model's answer is: knowledge production, in the service of building sociology's scholarly reputation. The main proposition underlying the answer is that the most constructive way to accomplish this is to adhere to philosophical, epistemological, ontological, theoretical and methodological principles and practices already in existence within, and recognized, by the discipline of sociology. In other words, the recommendation is that knowledge production within sociology is at its strongest when, so to speak, 'discipline-tied'. This, of course, does not mean that sociology should not be open to, and welcoming of, interdisciplinary 'borrowing' and collaboration (Puddephatt \& McLaughlin, in fact, do make a point to suggest that "we are already the most interdisciplinary of all the other traditional disciplines in the social sciences" (2015: 
316)), but that the foundation for the discipline's knowledge production ought to be set, and remain within, the discipline itself. This, the argument goes, would ensure the most credible, as well as least contentious, standards and criteria for the sound scientific research and practice, and, in turn, generate the most scholarly knowledge production.

The first point of consideration here builds on the earlier discussion of 'which — or whose - disciplinary history and tradition?', and can be stated as a related question of 'what — or whose — standards of sound sociological scholarship are we talking about?'. If we apply the previous logic of argumentation to this question as well, we end up with, substantively, the same kind of answer that whatever standards of sociological scholarship and knowledge production we settle on will, of necessity, be the standards that reflect the 'extra-sociological factors' that shape our sense of not only the nature, but also the purpose, of scholarly knowledge. In other words, given that, as sociologists, we are not producing knowledge for knowledge's sake but for the sake of maintaining and furthering sociology's scholarly reputation and credibility, this priorityand our understanding of what it takes to do it-will to a considerable extent impact our sense of what counts as the viable standards of 'sound scholarship'.

The second point of consideration is Puddephatt \& McLaughlin's caution against all-out interdisciplinarity on account that "[i]t is not clear that interdisciplinarity is universally superior to traditional disciplinary research, and many are critical of the room for amateurism and lack of standards that can result from the lack of qualified expertise brought to the table by disciplinary experts" (2015: 317). The suggestion here is that the discipline-specific standards of scientific research - because of being defined more clearly and grounded in (more or less) a disciplinary consensus - provide greater assurance that research will be of sound quality and thus (more) in line with credible scholarship. In a broader sense, the discipline-bound criteria also provide a more sound basis for navigating the "chaos" of institutional ambivalence within which the discipline of sociology exists and operates. While there is certainly a great deal of merit in arguing both points, one ought to be cautious not to overstate the case. Put simply, 'the room for amateurism and lack of standards' is, to some degree, likely to be present in scholarship that observes sociology-specific standards of research practises, and in scholarship that embraces interdisciplinary — or transdisciplinary_-'code of conduct'. In and of itself, the existence of research standards, disciplinespecific or not, does not guarantee more trustworthy scholarship. It may, but not always and not necessarily so. The professional-organizational model's likely response is that sociology-specific standards of research 
offer better 'quality control' of the discipline through the official outlets of scholarship (i.e. reputable sociological journals, sociology university presses, etc.). However, when considered in the light of the argument made above regarding the standards of sound scholarship, the (pro)position of this kind does not get us very far because all that it really points to is that there has to be some — or $a(n y)$ — standard of research practice against which the quality of scholarship can be assessed. All that matters, at the end of the day, is that this standard be accepted as viable by a community of scholarly peers. It can—but it doesn't have to-be disciplinespecific. A probable counterpoint to this is that sociologists, or any other social scientists, are more likely to accept as valid and sound a set of criteria internal, rather than external, to their discipline. This certainly may be, and perhaps is, the case. However, what it speaks to, more than anything else, is the 'logic' of embracing a given set of standards rather than an inherent, or demonstrable, pre-eminence of the standards themselves.

Finally, 'sociology_for whom?'. Differently from the public-political model, the professional-organizational model is not as explicit, or specific, about the end-users of sociological knowledge. One of the sources of institutional ambivalence identified by Puddephatt and McLaughlin is a tension between professional vs. public research audience, and the competing pressures resulting from the focus on either of these: an allegiance to fellow sociologists and sociology professionals as the principal audience has the benefit of "maintain[ing] the solid peer-review processes that assure strong scientific credibility", but the potential drawback of "alienat[ing] our publics and misrepresent[ing] or mischaracteriz[ing] their perspectives" (2015: 324); a closer tie to the public has an advantage of making sociological research more relevant to real people in the world, but the potential risk of 'arrogance surplus' by claiming too much expertise over the groups sociologists are working with/for and whose interests they are supposedly serving. While the reality of this particular source of institutional ambivalence is well taken, an argument can be made that both professional and public audiences are of, so to speak, 'second' rather then 'first' order. Another way to put this would be to suggest that, in the context of the overall proposition made by the professional-organizational model, there seems to be an implicit hierarchy of sociological research audiences, the top of which is populated by 'the deciders' of the discipline's institutional future. This, effectively, is an audience of ultimate consequence to sociology as an academic enterprise, and therefore the audience the discipline is in need of endearing itself to. This, of course, does not mean that other types of research audience - professional or public - are of no consequence to sociology. They most certainly are. However, their primary signifi- 
cance rests in figuring as the discipline's 'reputation builders' and, as such, the "stratagems" in sociology's 'game of academic survival'. True, professional and public research audiences are there because they are indispensable to sociology. However, the reason why they are indispensable goes well beyond why they are there. And it is precisely this that, in the grand scheme of things, makes them the audiences of second-order importance.

\section{Conclusion}

How do the public-political and professional-organization models of sociology fare against the 'pulse' of the Canadian sociological landscape? Joseph Machalski's 2004-2005 survey of Canadian sociologists, and its follow-up a decade later, provide instructive insights in this regard (Michalski 2015). Based on a random sample of some 350 full-time members of Sociology departments across Canada (yielding a 52.7\% response rate), the survey reveals that only $27 \%$ of Canadian sociologists believe that sociology is a distinct academic discipline, while the $64 \%$ hold the view that the discipline overlaps with other social science fields. Further, the majority of Canadian sociologists (i.e. 66\%) identify some version of critical epistemology (interpretive, feminist, postmodern, or other) as their epistemological orientation, while less than $20 \%$ claim some version of positivism as their epistemological standpoint. ${ }^{1}$ Moreover, less than two in five of Canadian sociologists refer to themselves as "sociologists" or "sociology professors" and, instead, 'label' themselves in nearly forty different ways. Finally, when it comes to the overall 'thrust' of sociological research in Canada, social justice orientation grounded in critical epistemology of one sort or another appears to predominate. While Machalski's work is still ongoing and his findings are therefore not conclusive, the data so far seem to indicate that, of the two models of sociology, the public-political is closer to the conscience collectif of Canadian sociologists. This, of course, does not mean that the professional-organizational model has no 'Canadian appeal' but, rather, that it appears to resonate with a (fairly sizable) minority of Canadian sociologists.

1. A breakdown of Canadian sociologists' specific epistemological orientations, in percentages, is as follows: Positivist-Scientific (13.8\%), Interpretive Social Science (9.6\%), Positivist-Interpretive (5.3\%), Critical Perspective (21.3\%), Critical Interpretive (8.0\%), Critical-Feminist (10.1\%), Critical-FeministInterpretive (9.6\%), Critical-Feminist-Postmodern (9.6\%), Postmodern + Critical/Interpretive (6.9\%), Eclectic/Other (5.9\%). 
Another, albeit anecdotal, metric of the sociological conscience collectif in Canada is a design of the official t-shirt of Canadian Sociological Association (CSA). Created in 2013, following the controversial remarks made by the then Canadian Prime Minister Stephen Harper, the front of the t-shirt reads 'commit sociology' (with a maple leaf underneath, added in 2015), while the back reads 'Canadian Sociological Association/La Société Canadienne de Sociologie - committing sociology since 1965'. According to Mervyn Horgan, the CSA executive committee secretary, the t-shirt was devised as CSA's response to the PM's comments, and has proven to be very popular and, it would appear, 'good for the profile of the discipline'. As he remarks, "I didn't intend the tagline on the back to be an official motto or anything like that, but it resonates as an unofficial one!" (personal communication, June 17, 2015). Official or not, the 'committing sociology since 1965 ' tagline seams to appeal to Canadian sociologists (and other social scientists):

No one has objected to the slogan. Even if someone doesn't purchase, they seem to chuckle and acknowledge the reference. We found in both years [2013 and 2015] that people from other associations came to us for a shirt after seeing it worn at Congress. Several people purchase shirts for friends/family/colleagues back home as well. ${ }^{2}$ (S. Fox, personal communication, June 17, 2015)

While anecdotal, the 'CSA t-shirt metric' is not altogether insignificant in that it suggests a particular way in which Canadian sociology regards and positions itself both professionally and in relation to Canadian society and (a particular instance of) its official political discourse. Its centerpiece is an attitude of defiance of a politically conservative (pro)position that 'sociologizing' has no place in society's public affairs (especially if the latter are contentious), and, by implication, a counter-(pro)position that 'sociologizing' in fact ought to engage and inform the public and political discourse of Canadian society. In other words, what the 'CSA t-shirt metric' seems to reveal is a disposition of Canadian sociology grounded in a self-regard and self-positioning as 'committed and engaged' - and thus meaningful and relevant—-social science undertaking. At its core, this disposition appears to be closer to the public-political model's understanding of sociology than to the one offered by the professional-organizational model.

2. Regarding t-shirt sales, all 255 units made for the 2013 CSA Conference in Victoria sold out within six months, while $50 \%$ of 356 t-shirts made for the 2015 CSA Conference in Ottawa sold onsite (with the remaining stock available for sale online) (S. Fox, personal communication, June 17, 2015). 
One last question to entertain: are the public-political and professional-organizational models either/or propositions? Yes, and no. 'Yes', if measured by the metric of sociology's 'final frontier' - that is to say, by the fact that the public-political model's ultimate vision of sociology's future is trans-national and post-sociological, while the one cast by the professional-organizational model is national and decidedly sociological. 'No' (or, perhaps more accurately, 'not necessarily so'), if thought of as the 'cartographies' of an ever-evolving sociological landscape aiming to map out its unfolding geography. If considered as such, as the 'maps' of the landscape yet to be, what emerges are the points of complementarity that inform what otherwise appear as two divergent visions for, and versions of, sociology. In other words, if what is offered by the two models is thought of as the indications of future trends for sociology rather than diagnoses of the discipline's fate then it perhaps becomes conceivable to think of Carroll's discourse on sociology as something that, at least in part, ads to the topography of Puddephatt \& McLaughlin's counterdiscourse, and, in turn, of Puddephatt \& McLaughlin's counter-discourse as something that, at least to some degree, offers an additional texture to the topography of Carroll's discourse. After all is said and done, it may well be that these 'elective affinities' between the two models are, in fact, the beginnings of a path towards a new understanding of the future of sociology.

\section{REFERENCES}

Agger, Ben. 2007. Public sociology : from social facts to literary acts. Lanham, Md.: Rowman \& Littlefield Publishers.

Bauman, Zygmunt. 1988. "Is there a Postmodern Sociology." Theory, Culture \& Society 5(2):217-37.

Beck, Urlich. 2007. "The Cosmopolitan Condition: Why Methodological Nationalism Fails." Theory, Culture \& Society 24(7-8):286-90.

Burawoy, Michael. 2005. "Third-wave sociology and the end of pure science." The American Sociologist 36(3/4):152-65.

Carroll, William K. 2013. "Discipline, Field, Nexus: Re-Visioning Sociology." Canadian Review of Sociology/Revue canadienne de sociologie 50(1):126.

Clawson, Dan, Robert Zussman, Joya Misra, Naomi Gerstel, Randall Stokes, and Douglas L. Anderton (Eds.). 2007. Public Sociology: Fifteen Eminent Sociologists Debate Politics and the Profession in the Twenty-first Century. Berkeley and Los Angeles: University of California Press. 
Freire, Paulo. 2000. Pedagogy of the Oppressed: 30th Anniversary Edition. New York: Bloomsbury Academic.

Friedrichs, Robert W. 1970. A Sociology of Sociology. New York: The Free Press.

Habermas, Jürgen. 1987. The Theory of Communicative Action (vol. 2). Boston: Beacon Press.

Levine, Donald Nathan. 1995. Visions of the sociological tradition. Chicago: University of Chicago Press.

Marx, Karl. 1978. “Theses on Feuerbach.” Pp. 143-45 in The Marx-Engels Reader, edited by Robert C. Tucker. New York: W. W. Norton \& Company.

Michalski, Joseph H. 2015. "The Epistemological Diversity of Canadian Sociology." Presented at the Annual Canadian Sociological Association Conference. Ottawa, ON.

Mills, C.Wright. 1959. The Sociological Imagination. New York: Oxford University Press.

Nichols, Lawrence T. 2007. Public sociology : the contemporary debate. New Brunswick, N.J.: Transaction Publishers.

Puddephatt, Antony J., and Neil McLaughlin. 2015. "Critical Nexus or Pluralist Discipline?: Institutional Ambivalence and the Future of Canadian Sociology." Canadian Review of Sociology/Revue canadienne de sociologie 52(3):310-32.

Ritzer, George. 1975. "Sociology: A Multiple Paradigm Science." The American Sociologist 10(3):156-67.

Saint-Simon, Claude Henri de. 1974. Social Organization, the Science of Man, and Other Writings. New York: Harper \& Row.

Zeitlin, Irving M. 1987. Ideology and the Development of Sociological Theory. Englewood Cliffs, NJ: Prentice-Hall.

Dalibor Mišina earned his $\mathrm{PhD}$ in sociology from the University of Alberta in Edmonton, Alberta. He currently holds a position of Assistant Professor in the Department of Sociology at Lakehead University in Thunder Bay, Ontario. His research interests include the areas of sociological theory, media and popular culture, and social transformations and change. His monograph Shake, Rattle and Roll: Yugoslav Rock Music and the Poetics of Social Critique was published in 2013 by Ashgate.

dmisina@lakeheadu.ca 